\title{
Urban walkers in medium-sized Portuguese cities: a study of Guimarães and Braga
}

\author{
K. R. Rahaman ${ }^{1}$, T. Alves $^{2}$ \& J. M. Lourenço ${ }^{1}$ \\ ${ }^{I}$ Department of Civil Engineering, University of Minho, Portugal \\ ${ }^{2}$ Center of Geography Studies, University of Lisbon, Portugal
}

\begin{abstract}
People are walking in cities for different reasons. Some walkers walk to go to work, some walk for shopping and some walk for leisure during day and night hours. Medium-sized cities, such as Braga and Guimarães in Portugal, depend on cars for even short trips of up to 2 kilometres. However, the walkways are allowing people to walk conveniently and safely, including in the late night environment. The pedestrians feel it is troublesome to walk on the footpaths because of illegal parking and the discontinuation of walkways. This paper focuses on the types of walkers who use the walkways on a regular basis. Usually, people feel comfortable walking when they go to clubs and bars in a group in these small cities, especially after work. This paper tries to focus the variety of problems on walkways and to present policies that can improve the situation. Field surveys have been conducted, both in the form of a questionnaire and observation, during the end of 2009 and the results show different patterns of pedestrian behaviour as well as evidence that people get different experiences with problems while walking on the walkways in both surveyed towns. Considering the issues of sustainable mobility, this paper also tries to suggest policies to motivate more people to walk, especially in the medium-sized cities of Portugal.
\end{abstract}

Keywords: urban, pedestrians, Braga, Guimarães, Portugal.

\section{Introduction}

Walking is the oldest and most basic form of human transportation. It requires no fare, no fuel, no license, and no registration (Portland [6]). With the exception of devices to enhance the mobility of the disabled, walking demands no special 
equipment. Thus, walking is the most affordable and accessible mode of transport (Rahaman et al. [7]). Innovations in planning for pedestrians have occurred largely in response to environmental pressures. In the first half of the nineteenth century, the arcade offered protection from wheeled traffic as well as a clean, dry surface for walking when European streets were poorly drained, even treacherous (Zacharias [8]). In Portugal, the two largest cities, Lisbon and Porto, experienced successful revitalization attempts of their riverfronts and city centres during the second half of the 1990s, with special programs of widening the sidewalks to encourage more pedestrian activities (Carlos and Balsas [1]). However, medium-sized cities, such as Braga and Guimarães, are yet to be studied for pedestrianization and problems of walkers. This paper tries to highlight the problems of pedestrians on walkways in those two cities and to bring forward policies that may offer walkers a smooth and comfortable sidewalk environment.

\section{Objectives}

There are three specific objectives of this study, which are as follows:

a) explore the reasons for walking in the studied areas

b) what are the major problems while walking and

c) to recommend measures to offer comfortable walking in the studied cities.

\section{Study area}

Braga and Guimarães, two neighbouring northern municipalities in Portugal, have almost 250,000 inhabitants (according to the Portuguese Statistics 2009). The city centres of the heads of the municipalities have been considered as the study area for this study. Situated in the heart of Minho, Braga finds itself in a region of contrasts between the East and the West, from mountains, forests and fields to the great valleys, plains and fresh and green meadows. The town of Braga, with 100.000 inhabitants, dominates its municipality with a total resident population of 164192 inhabitants and with an area of 184 sq. km. (Braga Municipality Webpage, 2010). Administratively, Braga is the capital of the district, consisting of 14 municipalities including also Guimarães. In brief, Braga is an urban municipality and its head has long been in the top 5 most populated towns in Portugal. Braga and Guimarães are the two most important towns of the recently defined Quadrilateral. The Quadrilateral consists of four cities named as Braga, Guimarães, Barcelos and Famalicão. These four cities have formed the Quadrilateral as an attempt to resist the metropolitanization of their territories by Porto city. The valley areas are predominant, but they do not reach high altitudes, varying from $20 \mathrm{~m}$ to approximately to $570 \mathrm{~m}$, so that the sun exposure is, in general, good throughout most of the territory.

Guimarães is another northern city of Portugal that has a very rich cultural heritage. It will be European Capital of Culture in 2012. The municipality has a land area consisting of almost $241 \mathrm{sq}$. km with 161,000 inhabitants (Guimarães Municipality Webpage, 2010). However, its head consists of 40.000 inhabitants. 
Over many years, Guimarães city officials pursued a policy of preserving architectural forms and rededicating spaces to new functions so that old and forgotten areas of the city centre were given a rebirth. Guimarães is the focus of greater levels of interest and recognition, both nationally as the first capital of Portugal and internationally, as a result of the city's strong commitment to the criteria it adopted and craftsmanship it supported in this area. The last thirty years have testified the accomplishment of some old projects and ambitions. The renovation of public spaces and of municipal buildings, dedicating them to new functions and services, along with the technical and financial support for private initiatives, represent the three main strategies that have helped in achieving the prime goals for the Historic City Centre of Guimarães. Those goals were basically as follows:

- First, the renovation of the landmarks in the Historic City Centre strove for the highest level of authenticity by using traditional materials and techniques, an ideal that not only maintained the architectural integrity, but also respected the quality of form and function.

- Second, the number and type of residents living in the Historic City Centre should maintain the living conditions of this population: improved and gentrification was not welcomed.

Both municipalities of Braga and Guimarães have an urban planning department that is taking care of execution, implementation, strategies and further urban planning scenarios in the city jurisdiction. However, the Municipality of Guimarães has had, since the late 1970s, a specific department dealing with the city centre. It has been recently incorporated in the urban planning department. Pedestrianization plans and strategies are being taken care of by the municipalities too.

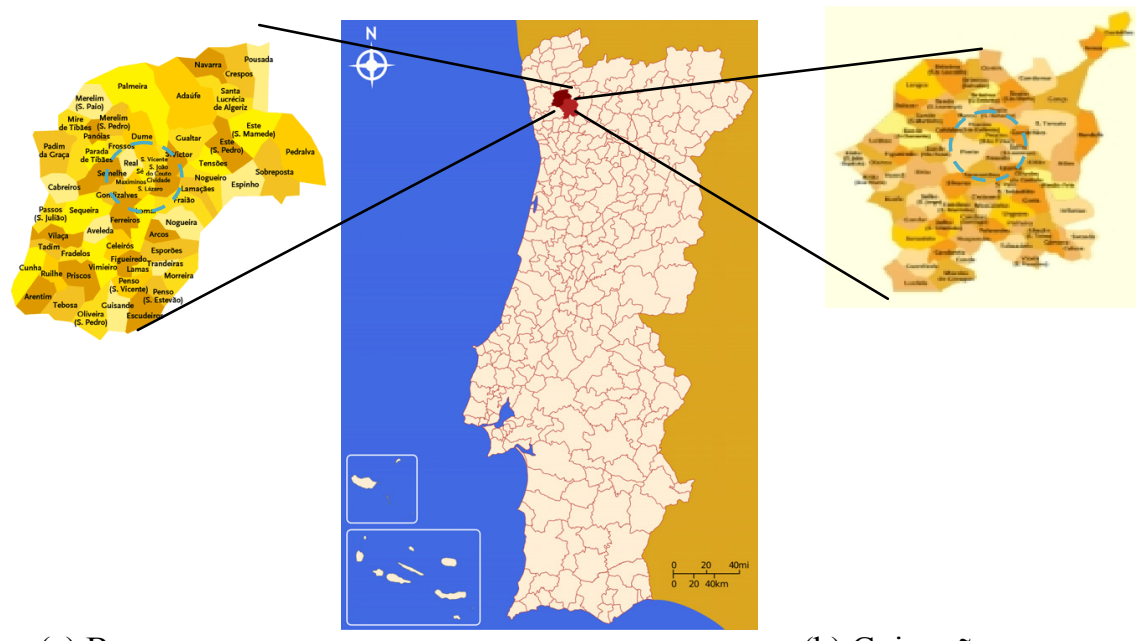

(a) Braga

(b) Guimarães

Figure 1: Map of Braga and Guimarães municipalities. 


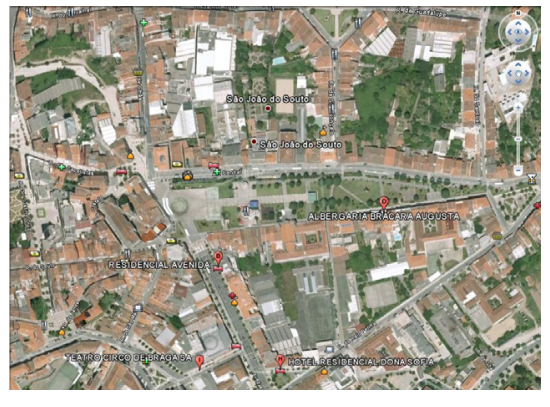

(a) Braga

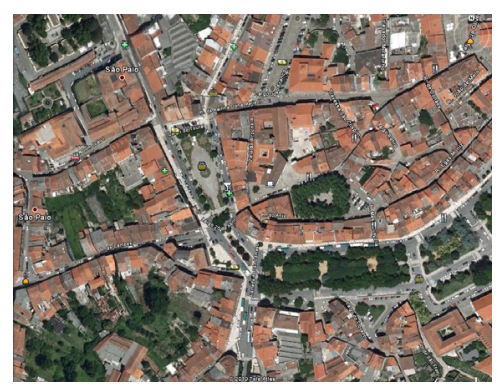

(b) Guimarães

Figure 2: Detailed city centre map, Braga and Guimarães (Google Earth, not to scale).

The city centre areas of both Braga and Guimarães have been surveyed to collect information related to the pedestrian flows and problems of walkers, as well as some short interviews of local residents. Figure $1(a, b)$ shows the location of Braga and Guimarães municipalities in Portugal and Figure 2 (a, b) shows the centre study areas of the two studied cities. The streets in the city centre areas have been considered for surveys and questions.

According to the municipality plans of Braga and Guimarães, the engineering departments are responsible for building and maintenance of the sidewalks in the city centres. The funds come from the central and local government for any improvement of sidewalks in the city centres in Braga and Guimarães. These two cities are quite walking friendly in nature. However, due to physical constraints of the cities, sometimes it is rather difficult to walk. Lots of tourists are coming every year in both the cities and exploring the city by walking.

\section{Methodology}

A simple method has been applied to collect and analyze data. Questionnaire surveys have been conducted to get the information related to reasons for walking, problems of walkways and other socio-economic data. An observation survey has been carried out at different times of the day and night to count the number of walkers and to establish the pedestrian speed of walkers in both the studied cities.

Photographs of walkways from both cities have also been analyzed to establish the problems of the pedestrians. After collecting the necessary information, simple statistical methods have been applied to summarize data to present the major findings of the study.

A sample survey has been conducted in form of a questionnaire to interview 100 people in Braga and Guimarães. An observation survey have been carried out in the form of counting the pedestrian flow, considering pedestrian speed, elevation of the walkways, pedestrian signs and bill boards, etc. Conceptual frameworks of problem identifications have been reviewed from literatures to 


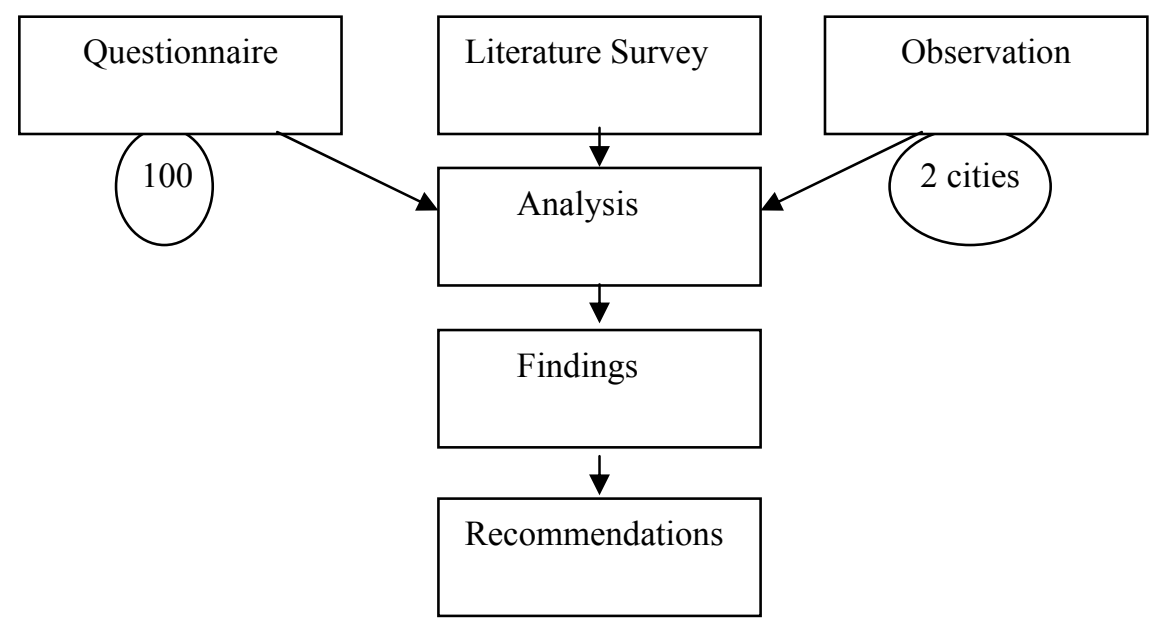

Figure 3: Diagrammatical sketch of the study method.

establish the typologies of the problems in these two cities. Four major factors have been assessed to establish the existing problems of the sidewalks and walkways in the studied cities. These are:

a) Functional Problems: functional features in this framework relate to the physical attributes of the street and path that reflect the fundamental structural aspects of the local environment.

b) Safety: this feature reflects the need to provide safe physical environments for people, considering crossing aids, lighting at night, etc.

c) Aesthetic: this includes the cleanliness, street maintenance and architectural propositions of the walkways in the existing set up.

d) Destination: this feature relates to the availability of local facilities and connection of the walkways with different urban services.

These classified problems have been explored in two cities in Portugal through a field survey.

\section{Who are the walkers in Braga and Guimarães?}

Recent guidelines for physical activity recommend that adults accumulate, on most days, 30 minutes or more of moderate-intensity physical activity (such as brisk walking), in minimum bouts of around 10 minutes (Pikora et. al. [5]). The transport research unit of Oxford University has unveiled information (2005) that in Portugal, $49.9 \%$ of the families have at least one car. During the last couple of years, car ownership in Portuguese cities grew even faster and it has been predicted that at least $68 \%$ of families have a car in 2008 (Dargay [2]). This means people are depending heavily on cars even for short trips. However, Braga and Guimarães city centres are very well designed for walkers, so that people can shop and can walk for leisure. For instance, different walkers in terms of age can be seen on the city centre streets of Braga and Guimarães. 
Table 1: $\quad$ Walking statistics of people in Braga based on age.

\begin{tabular}{|l|c|c|c|c|}
\hline Time Segments & $\begin{array}{c}\text { Youth } \\
(0 \text { to 15) }\end{array}$ & $\begin{array}{c}\text { Young } \\
\text { Adults } \\
\text { (15 to 40) }\end{array}$ & $\begin{array}{c}\text { Adults } \\
(40 \text { to 65) }\end{array}$ & $\begin{array}{c}\text { Elderly } \\
(65+)\end{array}$ \\
\hline Morning (up to 12 AM) & & & & \\
\hline Lunch Hour (12 to 15.00 PM) & & & & \\
\hline Afternoon (15h-17h) & & & & \\
\hline Afternoon(17h-20h) & & & & \\
\hline Night (20-23h) & & & & \\
\hline Night (23-2h) & & & & \\
\hline Night (After 2h) & & & & \\
\hline
\end{tabular}

(Source: Field Survey, 2009)

Table 2: $\quad$ Walking statistics of people in Guimarães based on age.

\begin{tabular}{|l|c|c|c|c|}
\hline Time Segments & $\begin{array}{c}\text { Youth } \\
(0 \text { to } 15)\end{array}$ & $\begin{array}{c}\text { Young } \\
\text { Adults } \\
\text { (15 to 40) }\end{array}$ & $\begin{array}{c}\text { Adults } \\
(40 \text { to 65) }\end{array}$ & $\begin{array}{c}\text { Elderly } \\
(65+)\end{array}$ \\
\hline Morning (up to 12 AM) & & & & \\
\hline Lunch Hour (12 to 15.00 PM) & & & & \\
\hline Afternoon (15h-17h) & & & & \\
\hline Afternoon(17h-20h) & & & & \\
\hline Night (20-23h) & & & & \\
\hline Night (23-2h) & & & & \\
\hline Night (After $2 \mathrm{~h})$ & & & \\
\hline
\end{tabular}

Legend:

\begin{tabular}{|l|l|}
\hline Less than $\leq 20 \%$ & \\
\hline $20 \%<$ Medium Low $\leq 35 \%$ & \\
\hline $35 \%<$ Medium $\leq 50 \%$ & \\
\hline $50 \%<$ High $\leq 65 \%$ & \\
\hline Very high $>65 \%$ & \\
\hline
\end{tabular}

From table 1, it can be seen that young adults (age group 15 to 40) are walking more at night during 20 to 2 PM in Braga. The situation is very similar in Guimarães, although a significant number of youths walk in the same time period. Indeed, the young adults are going to bars or clubs during this time and they rely on walking to go to those facilities. It has also been noticed that elderly people (65 or more age group) are walking during the day time from morning to late afternoon for shopping, leisure and other matters.

Tables 3 and 4 show different walkers based on their occupation. It has been observed that the retired persons are walking mostly in the morning for recreation, leisure or for entertainment. However, retired persons do not feel comfortable enough to walk during the night or even in the late afternoon. Students and unemployed people are walking more during the late evening and night. Indeed, these people are walking in a group of 5 to 10 persons to go to bars and pubs. Professionals, such as Engineers, Teachers, Administrators, etc., are walking for shorter trips up to 15 minutes from home or workplace to go for 
shopping or bringing their children back home from schools. The professionals are walking more during the evening time. Late at night, only some students and unemployed persons can be seen on the walkways and this is especially so at the weekend. Those walkers walk back home from the bars or nearest restaurants to their house.

Apart from these general observations that apply in both towns, differences can be depicted from tables 3 and 4 . The city centre of Guimarães concentrates in relative terms more bars and restaurants than Braga's. As the town of Guimarães is smaller in size and has a smaller city centre, it is closer to nearby areas. This may be the most important reason why significant numbers of students and professionals concentrate in the city centre. An additional reason might be the special atmosphere that Guimarães medieval open air city centre offers to the high number of users at night. This strong intensity of walkers shows clear evidence in the survey results. There is a very high intensity of pedestrian flows late at night (20.00 to 02.00 hours) in comparison to Braga, where the pedestrian flows do not show peaks either during day or night hours.

\section{Problems experienced by pedestrians}

While there are numerous challenges to pedestrian mobility and sidewalk accessibility, some are more likely to be experienced by small and medium-sized

Table 3: Walkers in Braga according to professions.

\begin{tabular}{|l|l|l|l|l|}
\hline Braga & Students & Professionals & Retired & Unemployed \\
\hline Morning (7-12) & & & & \\
\hline Lunch (12-15) & & & & \\
\hline Afternoon (15-17) & & & & \\
\hline Afternoon (17-20) & & & & \\
\hline Night (20-23) & & & & \\
\hline Night (23-2) & & & & \\
\hline Night (2 and later) & & & & \\
\hline
\end{tabular}

(Source: Field Survey 2009)

Table 4: Walkers in Guimarães according to professions.

\begin{tabular}{|l|l|l|l|l|}
\hline Guimarães & Students & Professionals & Retired & Unemployed \\
\hline Morning (7-12) & & & & \\
\hline Lunch (12-15) & & & & \\
\hline Afternoon (15-17) & & & & \\
\hline Afternoon (17-20) & & & & \\
\hline Night $(20-23)$ & & & \\
\hline Night $(23-2)$ & & & \\
\hline Night $(2$ and later) & & & \\
\hline Legend & & \\
\hline Low $\leq 20 \%$ & & \\
\hline $20 \%<$ Average Low $\leq 35 \%$ & \\
\hline $35 \%<$ Medium $\leq 50 \%$ & \\
\hline $50 \%<$ High $\leq 65 \%$ & \\
\hline Very High $>65 \%$ & & \\
\hline
\end{tabular}


cities (Evans [3]). Braga and Guimarães are two medium-sized cities in Portugal that are also having problems on sidewalks and walking ways at intersections. These problems have been studied through a literature review and field observations have been performed in both city centres. Considering all the observation surveys in these two cities, relevant problems have been identified. It has also been observed that some of the mentioned factors worked very well and others are still leading to unpleasant and inconvenient walkways in Braga and Guimarães. The identified walkway problems are now discussed.

Lack of Pedestrian Planning: transportation planning, especially in small and medium-sized cities, has typically focused on motorized traffic on streets (Evans [3]). This situation is not exceptional in Braga and Guimarães. Both municipal authorities have an engineering department that is preparing the city plans. However, pedestrians or bicycling plans are still absent in the municipal master plans. Some renderings can be seen in the road network design.

Lack of Walkway Maintenance: it has also been experienced from the observation survey that in Braga and Guimarães, walkways are not maintained well in some cases. In the city centre area, mostly the pavements, the colour of walkways and the continuity of walkways are well maintained. However, the connected pathways are not well maintained in most of the cases. The discontinuation of the width and length of walkways offers an inconvenient walking environment for pedestrians.

Figure 4 shows that the sidewalk has a lack of maintenance when it comes to describe the width. In this case, it has been measured that the sidewalk starts 1.2 metres wider in the beginning and in the middle it becomes less than 1 metre wide. The construction wall of the building comes into the right of way of the sidewalks and it offers an unpleasant and inconvenient sidewalk for the walkers. As a result, the walkers forcefully need to walk on the carriage way with cars, which decreases the safety of pedestrians.

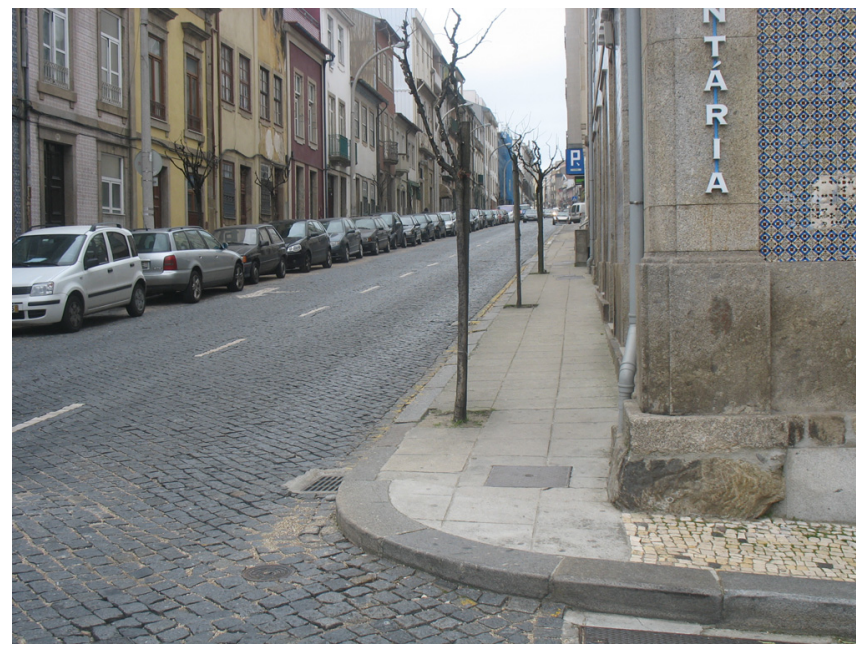

Figure 4: $\quad$ Poorly maintained width of sidewalks in Braga. 


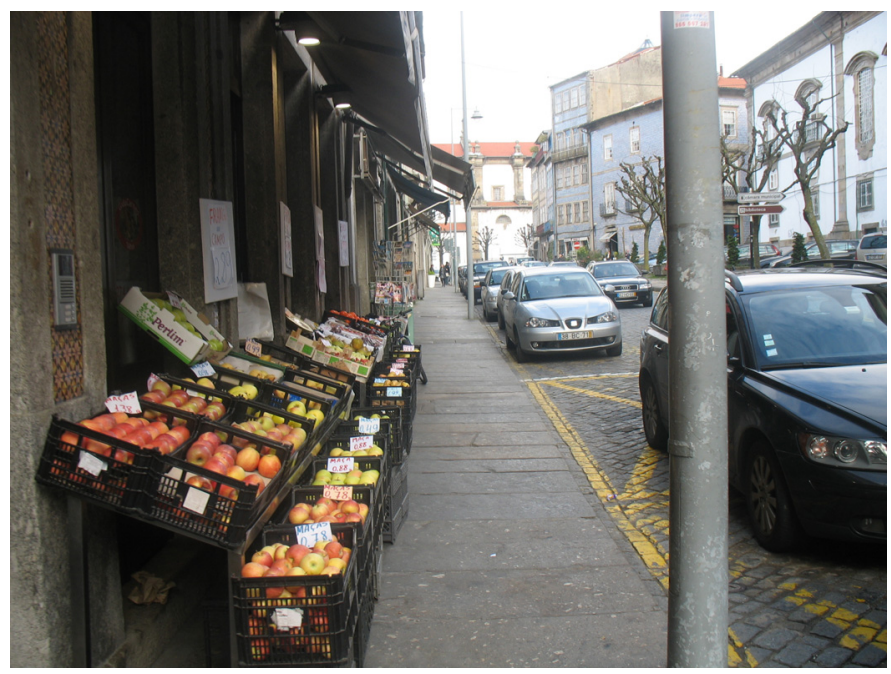

Figure 5: $\quad$ Encroachment of sidewalk width in Guimarães city centre area.

Figure 5 shows that the sidewalk has been taken by the shopkeeper to sell fruit products to the passerby. This situation is very common in medium-sized cities and it is also happening both in Braga and Guimarães. The cars are also going very fast on the adjacent sidewalks at almost 30 to $40 \mathrm{~km}$ per hour. Pedestrians can feel very uncomfortable crossing this area if two persons are walking in opposite directions.

Placement of unwanted hindrances on sidewalks: it has also been experienced in the studied areas that trees, electric pillars and dustbins are placed on the walkways to create a chaotic situation for pedestrians. In the busy sidewalks in mega cities like Tokyo, Mumbai and Mexico City, this scenario is not that common (Rahaman et al. [7]). However, in medium-sized cities like Braga and Guimarães in Portugal, some unwanted hindrances have been found even in the city centre streets. In figure 5 , it can be seen that a major electric pillar is placed on the sidewalk. It decreases the width of the walkway and at the same time it decreases the safety of the walkers. Sometimes, the dustbins and beautification trees (shown in figure 4) offer the same problem in small cities.

Lack of political and financial support for pedestrian planning: a major obstacle to achieving good pedestrian facilities is not just planning, it is implementation. Implementation is achieved through the dedication of resources by the public and from the resources of private property owners (Nelson [4]). In the studied municipalities in Portugal, the resources are mostly allocated to other sectors to negotiate the growing need of urban services, such as major infrastructures, housing, schools and shopping areas. However, pedestrian planning has been incorporated in the transportation plan in recent times, especially in Guimarães, because the city will be the European Capital of Culture in 2012. Certainly it will receive lots of tourists in 2012 and afterwards from home and abroad who will walk and see the city in coming years. 
Other problems for pedestrians, such as bus stop shades on walkways, street furniture, advertisement signs, broken man-holes, cars parking on walkways (mostly for a short time to drop people or to shop at the adjacent shops), etc., offer inconvenient pedestrian flow, especially in the day time.

\section{Conclusions}

Guimarães and Braga are traditionally being considered as pedestrian friendly city centres. They are two important cities in Portugal in terms of culture, tourism, business and service economy, located within a $12 \mathrm{Km}$ distance. Braga has an enormous area of pedestrian precinct in the city centre. These walkways are well connected with shopping areas and other city centre facilities. People of different ages are coming to the city centre for socialization, shopping and recreation purposes. Guimarães has a medieval city centre with connections to the shopping and tourist spots. Both cities have very nice and pedestrian friendly city centres. However, the dimensions of the city centres are different in terms of the number of pedestrians and the total length of walkways and the study shows different pedestrian mobility patterns in both cities that were not expected. These differences concern the age and professional status of the walkers. This induces a different schedule, both in the day and the night time, for pedestrian usage of the two city centres. This outcome is not widely known in regional policy making, but it should be considered when making urban and transportation plans.

This study pointed out some problems of pedestrians considering the types of walkers in two medium-sized cities in Portugal. Adjusted policies can improve the level of walkway services in these two cities if they are taken under consideration by the local authorities on a short and medium term basis.

First, the pedestrian plans should be prepared and revised along with the municipality transportation plan. Both Guimarães and Braga are receiving a significant number of tourists every year. Most of the tourist attractions exist within 20 minutes walking distance. As a result, tourists can also take the advantage of walking within the city in a convenient way if the pedestrian plan can be incorporated into the transport or into the urban planning system.

Second, maintenance of the walkways is important at regular intervals. In Braga city centre area, the walkways are well maintained, except for some width and colour alterations. In Guimarães city centre area, the walkways are offering alteration, both in form of width and length. Broken surfaces and up and down surfaces offer problems for smooth walking opportunities too. For instance, regular maintenance of walkways should be monitored closely by the municipality authority.

Albeit there has been a significant policy shift in which local governments are taking up increased responsibility in ensuring a safe pedestrian environment, much remains to be implemented. Representations of safer and convenient city walkways thus encourage more people to walk for shorter trips, which certainly leads to a healthy and carbon neutral city. This study is an attempt to propose a methodology for the quick assessment of walking environment problems in medium-sized cities. More empirical research is in demand to further develop 
this methodology. The importance of this approach is that less time is needed to apprehend the problems and to list and classify them. Likewise, more time can be devoted to problem discussion and finding of solutions within a public participatory atmosphere.

\section{Acknowledgements}

The authors would like to acknowledge the partial support given by the Portuguese Foundation for Science and Technology in the scope of the research project PTDC/GEO/64240/2006. This work was also partially supported by the FCT under grant no. SFRH/BPD/45762/2008. The authors are thankful to the MSc. students of Urban Engineering in the University of Minho for conducting the field survey, Fátima Matos $\left(4^{\text {th }} \mathrm{yr}\right.$ Civil Engineering Student) for summarizing field data and undergraduate civil engineering first year students for the observation survey in the field.

\section{References}

[1] Carlos, J.; Balsas, L, (2007), City Center Revitalization in Portugal: A Study of Lisbon and Porto, Journal of Urban Design, Vol. 12 (2), Routledge Publisher, UK, pp. $231-259$.

[2] Dargay, J., (2005), The Dynamics of Car Ownership in EU Countries: A Comparison Based on the European Household Panel Survey, Working Paper No. 1010, Transport Studies Unit, Oxford University Center for the Environment, the UK. p. 3.

[3] Jennifer Evans, (2006), Sidewalk Planning and Policies in Small Cities, Journal of Urban Planning and Development, ASCE, Vol. 132 (2), pp. $71-$ 75.

[4] Nelson, A.C., (1995), Private Provision of Public Pedestrian and Bicycle Access Ways: Public Policy Rationale and the Nature of Public and Private Benefits, TRR 1502, TRB, Washington D.C., pp. $96-104$.

[5] Pikora, Teri; Corti, Billie; Bull, Fiona; Jamrozik, Konrad; Donovan, Rob, (2003), Developing a Framework for Assessment of the Environmental Determinants of Walking and Cycling, Journal of Social Science and Medicine, Vol. 56 (2003), Elsevier Science, pp. 1693 - 1703.

[6] Portland Pedestrian Master Plan, (1998), City of Portland, Department of Transportation, USA, p. 1.

[7] Rahaman, Khan; Ohmori, Nobuaki; Harata, N., (2006), Evaluation of the Road side Walking Environment in Dhaka City, East Asian Studies of Transport Research, pp. $1751-1760$.

[8] Zacharias, John, (2001), Pedestrian Behaviour and Perception in Walking Environments, Journal of Planning Literature, Vol. 16 (1), Sage Publisher, pp. $3-18$.

[9] Braga Municipality, http://www.cm-braga.pt/ (Navigated on February 9, 2010 at 15.06 GMT) 
156 The Sustainable World

[10] Google Earth, www.googoleearth.com, navigated on January 2, 2010 at 11.32 GMT.

[11] Guimarães Municipality, http://www.cm-guimaraes.pt/, navigated on January 10, 2010 at 13.00 GMT. 